\title{
O Programa São Paulo Faz Escola e a proposta curricular paulista na visão dos professores
}

The São Paulo Faz Escola Program and the curricular proposal of São Paulo state in the teachers' perception

\section{El Programa São Paulo Faz Escola y la propuesta curricular de São Paulo en la visión de los maestros}

\author{
Daiani Vieira Ortega ${ }^{1}$ \\ Silvio Cesar Nunes Militão ${ }^{1}$
}

DOI: http://dx.doi.org/10.20435/serie-estudos.v26i56.1431

\begin{abstract}
Resumo: Este artigo resulta de uma pesquisa empírica realizada entre 2017-2018, que buscou desvelar a percepção dos professores acerca da proposta curricular implementada a partir do Programa São Paulo Faz Escola (PSPFE) durante a gestão de José Serra (2007-2010). Diante do objetivo precípuo e a partir de uma abordagem qualitativa, realizou-se um estudo de caso em uma escola do interior do estado de São Paulo e coletaram-se os dados a partir de entrevistas semiestruturadas realizadas com nove professores. Os resultados da pesquisa apontam que a falta de participação dos professores na formulação da proposta e as diferenças de concepção de educação presentes nela foram responsáveis pela rejeição dos professores e adoção de estratégias de resistência. Viu-se que, mesmo diante do conjunto de ações que visaram garantir a consolidação da proposta (EFAP, SARESP, Bônus), os professores refletem sobre a prática pedagógica e adotam estratégias para construir um conhecimento contextualizado com a realidade dos seus alunos.
\end{abstract}

Palavras-chave: proposta curricular; Programa São Paulo Faz Escola; Estado de São Paulo.

\begin{abstract}
This article results from empirical research conducted from 2017-2018, which sought to reveal the teachers' perception about the curricular proposal implemented from the São Paulo Faz Escola program (PSPFE) during the management of José Serra (2007-2010). Given the primary objective and from a qualitative approach, we conducted a case study in a school from the interior of São Paulo state, where the data was collected using semi-structured interviews conducted with nine teachers. The research results indicate that teachers' lack of participation in the formulation of the curricular proposal and the differences in the conception of education present in it are responsible for the rejection by teachers and adoption of resistance strategies. We saw that, even in the face of the set of actions that aimed to ensure the consolidation of the reform (EFAP,
\end{abstract}

\footnotetext{
1 Universidade Estadual Paulista (UNESP), Presidente Prudente, São Paulo, Brasil.
} 
SARESP, and Bonus), the teachers reflect on pedagogical practice and adopt strategies to build a knowledge contextualized with the reality of their students.

Keywords: curricular proposal; São Paulo Faz Escola Program; São Paulo state.

Resumen: Este artículo es el resultado de una investigación empírica realizada entre 2017 y 2018, que buscó revelar la percepción de los maestros sobre la propuesta curricular implementada del Programa São Paulo Faz Escola (PSPFE) durante la gestión José Serra (2007-2010). Dado el objetivo principal y desde un enfoque cualitativo, se realizó un estudio de caso en una escuela en el interior del estado de São Paulo y se recopilaron datos de entrevistas semiestructuradas con nueve maestros. Los resultados de la investigación indican que la falta de participación de los docentes en la formulación de la propuesta y las diferencias en la concepción de la educación presente en ella fueron responsables del rechazo de los docentes y adopción de estrategias de resistencia. Vimos que, incluso con el conjunto de acciones destinadas a garantizar la consolidación de la propuesta (EFAP, SARESP, Bonus), los docentes reflexionan sobre la práctica pedagógica y adoptan estrategias para construir un conocimiento contextualizado con la realidad de sus alumnos.

Palabras clave: propuesta curricular; Programa São Paulo Faz Escola; Estado de São Paulo.

\section{INTRODUÇÃO}

Na gestão de José Serra (2007-2010), a política educacional foi orientada pelas diretrizes estabelecidas na Nova Agenda para a Educação Paulista, por meio da qual selecionaram-se mecanismos de unificação, controle e monitoramento de toda a rede pública de ensino, dos quais destaca-se a implementação de uma nova proposta curricular nas escolas estaduais paulistas, a partir do Programa São Paulo Faz Escola (PSPFE), argumentando-se que era necessário padronizar o trabalho pedagógico em toda a rede de ensino, já que os índices dos alunos nas principais avaliações (Sistema de Avaliação do Rendimento do Estado de São Paulo [SARESP], Sistema de Avaliação da Educação Básica [SAEB] e Exame Nacional do Ensino Médio [ENEM]) eram insatisfatórios (CASTRO, 2007).

Com o PSPFE, um conjunto de materiais didáticos foi formulado por um grupo de experts em educação e em currículo, seguindo a tendência neoliberal de que, para garantir maior eficiência e produtividade com recursos escassos, seria necessário promover consultas a especialistas (GENTILI, 1998).

Inicialmente, os gestores receberam um caderno de orientações que os colocava como os principais implementadores da proposta curricular. Para os professores, foram destinadas revistas prescritivas que direcionavam um trabalho voltado à recuperação das defasagens de aprendizagem nos primeiros 42 dias do 
ano letivo de 2008, e aos alunos foi disponibilizado um material de recuperação em formato de jornal.

Posteriormente, as escolas receberam as propostas curriculares de cada grande área do conhecimento, acompanhadas dos Cadernos do Professor, em que vinha especificado o passo a passo a ser seguido em cada aula, e do Caderno do Aluno, material consumível contendo atividades de cada disciplina.

Esses materiais tornaram-se parte do cotidiano escolar, e as cobranças para que seu uso acontecesse na íntegra foram ocorrendo de forma sistematizada. A falta de participação dos professores na formulação dessa política os fez recebê-la com grande desconfiança, pois a proposta curricular, com moldes prescritivos, criou obstáculos para a contextualização do currículo às realidades locais.

Nesse contexto, realizou-se esta investigação com o intuito de entender o processo de implementação do PSPFE e da proposta curricular paulista e suas decorrências no trabalho docente. Buscou-se dar voz aos atores sociais que estão no chão da escola, vivem as angústias do cotidiano e são silenciados e/ou têm suas vozes ignoradas no processo de formulação das políticas.

\section{METODOLOGIA}

Considerando que o objetivo precípuo da investigação foi analisar o processo de implementação do PSPFE e da proposta curricular paulista e suas decorrências no trabalho docente, a partir da percepção de professores de uma escola estadual paulista, optou-se pela realização de uma pesquisa de cunho qualitativo.

Diante do problema de pesquisa, elegeu-se o estudo de caso como a estratégia mais adequada para o levantamento dos dados necessários à sua compreensão, pois ele conduz a um aprofundamento na compreensão do fenômeno educacional, com ênfase na sua singularidade (TRIVIÑOS, 2011).

Com o estudo de caso, foi possível obter visibilidade daquilo que não está registrado, ou seja, como o PSPFE e a proposta curricular foram recebidos e entendidos pelos professores daquela unidade escolar em específico. A escola estudada servirá como caso representativo de uma realidade maior. "Mesmo que a realidade de uma escola não se repita em outras, alguns aspectos das relações estabelecidas podem fornecer dados para as questões mais amplas relativas a contextos de outras escolas" (CANTAZARO, 2012, p. 52). 
Entendeu-se que entrevistas semiestruturadas seriam a melhor opção diante do objetivo desta pesquisa, haja vista que se trata de uma técnica de pesquisa flexível, que permite correções e adaptações à medida que acontece.

O principal critério para a escolha dos participantes das entrevistas foi ter atuado na rede estadual de ensino no período anterior a 2008 e ter vivenciado o processo de implementação do PSPFE e da proposta curricular. Com base nesse critério, foram selecionados nove professores para participarem da entrevista, cujos perfis estão descritos no quadro abaixo.

Quadro 1 - Perfil dos participantes da pesquisa

\begin{tabular}{|c|l|}
\hline $\begin{array}{c}\text { Participantes } \\
\text { da pesquisa }\end{array}$ & \multicolumn{1}{c|}{ Perfil } \\
\hline P1 & $\begin{array}{l}\text { Professor de Matemática, 57 anos. Atua na escola pesquisada há } \\
19 \text { anos. }\end{array}$ \\
\hline P2 & $\begin{array}{l}\text { Professora de Língua Portuguesa, 39 anos. Atua na escola } \\
\text { pesquisada há 11 anos. }\end{array}$ \\
\hline P3 & $\begin{array}{l}\text { Professora de História, 49 anos. Ingressou na rede estadual no ano } \\
\text { de 2000 e esteve no cargo de professora coordenadora do Núcleo } \\
\text { Pedagógico de 2000 a 2018. }\end{array}$ \\
\hline P4 & $\begin{array}{l}\text { Professora de Matemática, 44 anos. Trabalha na escola pesquisada } \\
\text { há 13 anos. }\end{array}$ \\
\hline P5 & $\begin{array}{l}\text { Professora de Inglês e Língua Portuguesa, 57 anos. Atua na escola } \\
\text { pesquisada há 18 anos. }\end{array}$ \\
\hline P6 & $\begin{array}{l}\text { Professora de Língua Portuguesa, 43 anos. Atua na escola } \\
\text { pesquisada há 18 anos. }\end{array}$ \\
\hline P8 & $\begin{array}{l}\text { Professor de Física, 54 anos. Atua na escola cenário da pesquisa há } \\
\text { 23 anos. }\end{array}$ \\
\hline P9 & $\begin{array}{l}\text { Professor de Filosofia e Sociologia, 39 anos. Atua na escola } \\
\text { pesquisada há 10 anos. }\end{array}$ \\
\hline $\begin{array}{l}\text { Professora de Ciências, Biologia, Química e Matemática, 55 anos. } \\
\text { Atua na escola pesquisada há 14 anos. }\end{array}$ \\
\hline
\end{tabular}

Fonte: pesquisa realizada, 2018.

Seguiram-se princípios éticos para a realização da pesquisa de campo, explicitaram-se aos participantes os objetivos e métodos do trabalho e o sigilo 
sobre as informações compartilhadas. Para garantir o anonimato, identificaram-se os participantes com letra e número P1 a P9.

O roteiro de entrevista foi elaborado previamente para que atendesse aos objetivos da pesquisa, sendo subdividido em dois eixos: "O trabalho docente antes do PSPFE" e "A percepção docente sobre a proposta curricular advinda com o programa e suas implicações no cotidiano escolar". As entrevistas foram gravadas e transcritas, para então apreenderem-se os aspectos relacionados aos posicionamentos, relatos de vivência, reações e percepções dos sujeitos da pesquisa.

Os dados levantados, a partir das entrevistas, foram tratados mediante análise de conteúdo e organizados em categorias que permitiram apreender a percepção docente em relação ao trabalho pedagógico realizado no período anterior à implementação do PSPFE; a participação ou ausência de participação dos professores na formulação da proposta curricular e como essa política foi recebida pelo grupo dessa escola em particular; o que mudou no cotidiano escolar com a implementação da proposta; e a percepção do professor em relação a sua autonomia na ação educativa.

\section{A VOZ DOS PROFESSORES ACERCA DO PSPFE E DA PROPOSTA CURRICULAR PAULISTA:}

\subsection{Trabalho docente antes do PSPFE e o processo de implementação do programa}

Analisou-se a percepção dos participantes da pesquisa acerca do trabalho docente antes e depois da implementação do PSPFE e da proposta curricular, com o objetivo de apreender as alterações que eles trouxeram ao trabalho pedagógico escolar.

Encontrou-se um certo saudosismo na fala dos docentes do período anterior ao PSPFE e à proposta curricular. A fala do professor P1 indicou que, anteriormente, por controlar o seu saber fazer, ser livre para tomar decisões e conhecer as diversas necessidades de aprendizagem, o professor assenhorava-se da sala de aula com propriedade e confiança para desempenhar sua função. "Eu sabia onde os meus alunos estavam e eu tinha que partir dali e era aquilo que eu ia ensinar" (Professor P1, 2018). 
As falas evidenciaram que os professores entendem que o currículo cumpre a sua função a partir dos conteúdos e das práticas que são realizadas ao seu redor, não sendo possível tratá-lo como algo dado, mas sim identificar os valores e pressupostos que o permeiam, considerando o contexto de sua construção (SACRISTÁN, 2000).

Percebe-se que, antes do PSPFE, a preocupação dos professores era trabaIhar questões que envolviam aspectos importantes à convivência e ao respeito entre os alunos. A fala da professora P6 vem, nesse sentido, expressando a intenção em adotar um currículo constituído pelos conceitos de cidadania, educação, cultura e valores, formado o aluno para além da leitura e escrita, conforme preconizado pela própria Lei de Diretrizes e Bases da Educação Nacional (LDB), Lei n. 9.394/1996. "Então se tinha algum problema de indisciplina ou bullying, eu podia escolher um texto que viesse a calhar o assunto" (Professora P6, 2018).

As entrevistas evidenciaram também que, antes do PSPFE, outra política educacional de âmbito nacional assumiu expressiva relevância nas práticas educativas: o Programa Nacional do Livro Didático (PNLD).

Cabe ressaltar que muitas das políticas educacionais dos países em desenvolvimento, financiadas por organismos e agências internacionais como o Banco Mundial (BM), estiveram centradas nesse material, e, com a alocação de recursos para a compra dos livros, estes tornaram-se o centro das políticas educacionais e, muitas vezes, o próprio currículo do país (TORRES, 2000).

Nesse sentido, Munakata (2007) ressalta que os livros didáticos são responsáveis pela criação de uma base cultural mínima no seio da sociedade e, portanto, olhar para esse material e examiná-lo não é algo simples, sendo necessário considerar uma série de questões que vão desvelar interesses em todas as etapas da produção do livro, inclusive aqueles por trás da própria indústria editorial e da pré-seleção realizada pelo MEC.

Porém, diferentemente dos materiais apostilados, o livro didático dá uma falsa impressão aos professores de que seu trabalho não é rigidamente limitado, já que esse recurso parece oferecer maior flexibilidade para a organização e o planejamento das aulas. Além disso, no livro didático, é menos nítida a interferência de agentes externos em sua elaboração (DI GIORGI et al., 2014).

É importante considerar também que o PNLD sempre esteve intrinsecamente associado aos Parâmetros Curriculares Nacionais (PCN). Os livros didáticos 
produzidos e distribuídos do ano de 1998 em diante atendiam as premissas por eles estabelecidas. Todo o processo de escolha dos livros está condicionado às determinações dos PCN, já que os guias elaborados pelo MEC avaliam a pertinência e a adequação dos conteúdos dos livros a esses. Porém, por mais que a prática docente já fosse condicionada pelo Estado por meio de uma política educacional de grande alcance como os PCN, somente uma das participantes da pesquisa fez referência a ela como instrumento utilizado para a organização e o planejamento das aulas no período anterior à reforma. "A gente tinha os PCN que eram muito abertos e que davam um leque de A a Z em história" (Professora P3, 2018).

Infere-se que o fato de os PCN não terem sido citados revela que os professores não têm clareza do quanto aquela política já direcionava o trabalho pedagógico escolar, pois os mecanismos de controle estabelecidos a partir dos PCN não eram tão desenhados quanto aqueles que emergiram com o PSPFE.

Essas evidências reforçam o poder indutor dos materiais advindos com o PSPFE, pois ele se objetivou no cotidiano escolar, reduzindo consideravelmente as "brechas" para que outros materiais pudessem ser escolhidos e utilizados pelos professores, como veremos adiante.

Selecionamos elementos das falas dos sujeitos da pesquisa que se apresentam como subsídios para a compreensão de como se deu a participação dos professores na formulação da proposta e como ocorreu a implementação do PSPFE, buscando desvelar as mudanças ocasionadas pelo programa no trabalho docente.

Quando questionados sobre a apresentação do PSPFE, os professores logo a associaram à chegada dos jornais do aluno à escola. "O SPFE iniciou primeiro como jornal [...] as atividades vieram em formato de jornal" (Professor P2, 2018).

O jornal do aluno agradou aos participantes da pesquisa, pois, segundo eles, apresentavam atividades contextualizadas e de boa qualidade. Essa situação gerou boas expectativas no grupo de professores em relação ao que estava por vir. "O jornal tinha algumas coisas que a gente gostou bastante, bem voltada assim para a realidade, né. E o que a gente imaginou foi o seguinte, se a apostila tiver o mesmo formato do jornal vai ser legal" (Professor P7, 2018).

Cabe ressaltar que os materiais que vieram depois seguiram o mesmo formato da revista do professor e do jornal do aluno, focados no desenvolvimento de competências e habilidades. Acredita-se que a avaliação positiva inicial dos professores se deva ao fato de eles não terem uma visão mais nítida dos efeitos 
deletérios de tal material para a prática/autonomia escolar/pedagógica, bem como ao fato de não terem conseguido vislumbrar, naquele momento, o que esse material inicial se tornaria posteriormente (no currículo fechado para toda a rede).

No segundo bimestre, chegou às escolas a proposta curricular de cada disciplina, acompanhada do Caderno do Professor. Apesar do caráter prescritivo, de especificar conteúdos, habilidades, competências, metodologias, recursos pedagógicos e formas de avaliação, naquele momento parecia tratar-se de um material flexível, passivo de modificações e adaptação, como o livro didático. Entende-se que, nesse primeiro momento, os professores ainda não podiam imaginar todo o aparato que estava sendo montado para garantir a efetivação da política e, portanto, a rejeição a ela ainda era menor. "Ele chegou como uma proposta curricular, só o Caderno do Professor [...] Na verdade era uma orientação, não era assim um material que você tinha que seguir. Era um material de apoio mesmo" (Professor P1, 2018).

No ano seguinte, as escolas receberam um material parecido com a proposta, porém como uma nova denominação de Currículo Oficial Paulista e um novo Caderno do Professor, no qual não se podia notar grandes diferenças em relação ao entregue no ano anterior, por mais que na página do PSPFE constasse que o Caderno do Professor foi reestruturado segundo as sugestões que os professores fizeram na pesquisa on-line mencionada anteriormente.

Mas a grande novidade naquele momento ficava por conta de um novo material, denominado de Caderno do Aluno, que chegou às escolas em meados do mês de maio. Segundo os professores, assim como o jornal, não houve uma orientação prévia sobre seu uso e, por isso, a primeira reação foi a de negação.

De repente chega um material na mão, cheio de equívocos por parte da equipe gestora, por parte de todo mundo, ele tendo que usar um material que ele desconhecia. [...] Então, se tivesse tido uma discussão mais ampla, se tivesse tido um estudo, todo mundo tinha sofrido menos, talvez tivesse entendido melhor. Acho que o maior erro foi esse [...]. (Professora P3, 2018).

Como podemos observar, a rejeição ao PSPFE foi enfatizada pela maioria dos participantes da pesquisa. "De repente chega um material novo na escola", sem que os professores tivessem sido amplamente consultados, ouvidos como grandes conhecedores da realidade escolar. O desconhecimento sobre o que estava acontecendo, a surpresa a cada novo material que chegava às escolas, 
a necessidade de se adaptar rapidamente "às novidades" e a dificuldade em se encontrarem os caminhos sem orientação alguma deixam claro o porquê de tanta rejeição e insatisfação com o programa. Foi um "choque" para os professores, como bem coloca a participante P6. Implantava-se uma política verticalmente, de cima para baixo, sem qualquer consideração aos professores, seus saberes e sua experiência, reduzindo-os a meros espectadores.

Quando questionados sobre a participação dos professores na construção do currículo e dos materiais de apoio, ficou evidente o descontentamento da maioria dos participantes da pesquisa. Alguns responderam de forma breve, porém as expressões faciais e a ênfase dada no tom de voz ao dizer que não participaram e que não foram chamados para discutir sobre a elaboração dos materiais são elementos que precisam ser considerados nesta análise. "Não houve. Pelo menos nós aqui, da nossa escola, não participamos" (Professor P2, 2018).

A falta de participação na construção da proposta curricular e a consagração de grupos de especialistas, os experts em educação, para essa função, foram muito questionadas e têm relação direta com a negação e desconfiança que foi crescendo entre os professores à medida que os materiais chegavam às escolas.

[...] nós também questionamos isso na época, né... como que, por exemplo, as pessoas lá, os professores de São Paulo, como é que eles vão formular uma coisa se eles não conhecem a realidade, por exemplo, do interior? [...]. (Professor P6, 2018).

Portanto, as vozes dos sujeitos da pesquisa apontaram que a participação dos principais responsáveis pelo processo educativo, os professores, não foi considerada em nenhum momento da elaboração da proposta. Percebemos que, no ano anterior, pouco se havia falado sobre as eventuais mudanças, pois apenas a entrevistada que estava, na época, ocupando cargo na Diretoria de Ensino (DE) apontou ter ouvido comentários de que o currículo estava sendo elaborado, porém esse conhecimento limitou-se a "ouvir falar". "A gente sabia que o currículo estava sendo elaborado, né. Mas a gente não sabia direito quais universidades, o que que viria. A gente não sabia nada" (Professora P3, 2018).

A implementação do PSPFE e da proposta curricular, assim como outras ações adotadas no estado de São Paulo ao longo da gestão do PSDB, segue o Modelo Top Down (PRESSMAN; WILDAVSKI, 1973 apud RUA, 2013), abordagem racionalista que prevê uma implementação programada, na qual os implementadores 
seriam responsáveis para que a política acontecesse de fato, como foi pensada e programada, porém sem espaço para que suas vozes fossem ouvidas e suas experiências consideradas.

Desconsideram-se, nessa abordagem, as realidades locais e os sujeitos, vistos como se "não tivessem projetos, preferências e até clientelas políticas e atuassem puramente segundo o princípio da obediência às normas e às determinações dos políticos" (RUA, 2013, p. 7).

Segundo Capalbo (2010), o modelo de implementação de políticas educacionais que vemos se consolidar a partir da década de 1990, e tem no PSPFE um dos principais marcos, conduz a uma desvalorização cada vez mais intensa do professor e de sua experiência.

O que se percebe é um abandono do professor, uma desvalorização. A figura do professor não é mais a figura de um grande herói. Herói no sentido de exemplo a ser seguido, de espelho do outro na construção de sua autonomia. O que se tem visto é uma política de valorização da dependência, gerando a falta de liberdade pela ignorância. Qualquer pessoa é capaz de seguir uma receita. É assim que queremos o educador de hoje? (CAPALBO, 2010, p. 72).

O professor precisa ver em si a possibilidade de construção de sua prática e da valorização dessa, pois é ele que está dia a dia com o aluno. É a ele que cabe o papel fundamental na construção dos sujeitos. Por isso, é comum, entre o grupo, questionamentos como o da professora P5: "Quem está dentro da sala de aula? Quem convive com aluno? O professor. Não é? Quem consegue perceber a vivência do aluno, a bagagem do aluno? É o professor! E o professor em nenhum momento foi consultado" (Professor P5, 2018).

À medida que as políticas ignoram a importância do professor, tiram sua possibilidade autoral e evidenciam que os especialistas em educação estão distantes da sala de aula, abalam a própria identidade do professor (CAPALBO, 2010).

O PSPFE seguiu um modelo de fragmentação entre concepção e execução estabelecido nas primeiras gestões do governo PSDB no estado de São Paulo, em um contexto de ascensão e consolidação do pensamento neoliberal. Giroux (1997) corrobora esses apontamentos ao afirmar que as mudanças educacionais propostas, a partir dos anos de 1990, vêm representando ameaças aos professores, pois demonstram pouca confiança na capacidade deles e ignoram o papel 
social desses sujeitos em preparar as crianças e os jovens para atuarem como cidadãos ativos e críticos.

Da forma como o PSPFE foi implantado, infere-se que a Secretaria Estadual da Educação (SEE) esperava que ele chegasse a um ambiente vazio, com sujeitos passivos que seguiriam as determinações dos especialistas em educação sem questionamento algum, abrindo mão de sua autonomia e do trabalho criativo. Porém não é o que se constata dez anos após a inserção do programa no cotidiano escolar. Os professores têm seu lugar, são eles que tomam decisões dentro da sala de aula. São eles que recriam o currículo e the dão sentido e significado. Qualquer política que se queira exitosa precisa começar por eles, dando-Ihes voz.

Em relação aos mecanismos de implementação da proposta curricular, percebemos que impera entre os professores uma visão reducionista, pois o aparato montado pelo estado para dar sustentação ao PSPFE e à proposta não foi percebido pelos professores, já que nas falas sobressaiu-se a presença do Caderno do Aluno na escola.

Isso ficou evidente quando se questionou sobre outras ações implantadas pela SEE com relação ao PSPFE e viu-se que a maioria não identificou/relacionou os demais mecanismos que acompanharam sua implementação. "Então assim, eu não me lembro de ter nenhuma ação, eu me lembro de programas paralelos, mas ação voltada para o currículo com a intenção... não" (Professor P4, 2018).

A responsabilidade do PC em implementar o PSPFE, a intrínseca relação entre o programa e o SARESP; a criação do Portal de Apoio à Implantação do Currículo, com os vídeos e roteiros de formação em ATPC; o Programa Mais Qualidade na Escola e a etapa formativa oferecida pela EFAP aos ingressos do concurso de 2011, preparando os novos professores para o trabalho com o currículo e outras ações intrinsecamente atreladas ao programa, e muito bem planejadas no sentido de garantir a sua consolidação na prática, não foram apreendidas pelos professores. As ações percebidas por eles restringiram-se àquelas oferecidas na escala local, em nível de DE, como as capacitações oferecidas nos anos seguintes e o monitoramento do uso dos materiais do PSPFE.

O papel exercido pela DE foi visto pelos sujeitos da pesquisa de forma totalmente desconectada da política em si, pois eles atribuem essas ações como algo muito específico daquela localidade, acreditando que essa cobrança é exclusiva 
da DE à qual a escola pertence, o que evidencia que eles analisam o PSPFE e a proposta curricular por um viés puramente subjetivo.

Muitos equívocos aconteceram nesse momento. Um caça às bruxas mesmo, de a gente ficar sabendo que diretores tinham trancado, por desconhecimento mesmo do currículo, diretores que trancaram livros didáticos, não permitiam que os professores usassem livros didáticos ou outros materiais para forçar o professor a usar o currículo. O que foi um equívoco naquele momento de achar que o currículo era o caderno do aluno. (Professor P3, 2018).

Acreditamos que, por tratar-se de um município pequeno, o contato permanente com a DE é facilitado e, portanto, os instrumentos de controle por ela estabelecidos, como a presença constante dos PCNP nas escolas, foram tão enfatizados pelos professores.

\subsection{Implicações do PSPFE e da proposta curricular no trabalho docente: o caderno do aluno}

Entre os elementos advindos com o PSPFE, o Caderno do Aluno foi visto como o principal responsável por alterações no trabalho docente e no cotidiano escolar. Ao serem questionados sobre as mudanças no chão da escola, os participantes da pesquisa mencionaram com frequência a presença do Caderno do Aluno.

Por ser consumível e disponibilizado aos alunos, o material tornou-se um dos principais elementos constituintes do cotidiano escolar. Segundo Maldonado (2013), o fato de o material estar presente em vários espaços da escola e ser utilizado na célula de trabalho individual do professor, a sala de aula, justifica a percepção limitada do professor em relação ao PSPFE, como se esse se limitasse ao Caderno do Aluno.

A estrutura do material e a falta de contextualização dele estiveram entre os argumentos usados pelos professores ao recusarem-se a usá-lo quando esse chegou às escolas. "No início, ninguém trabalhava o Caderno do Aluno. Ninguém. O material chegava, a gente deixava lá" (Professora P6, 2018).

Além da grande quantidade de conteúdos a serem trabalhados por bimestre e do tempo insuficiente para isso, os professores encontraram outro obstáculo: entender a metodologia proposta no novo currículo. A proposta curricular fundamentou-se na "Pedagogia das Competências", defensora de uma educação em que os sujeitos devem se apropriar de um conjunto de competências e habilidades 
que os tornem capazes de mobilizar conhecimentos e saberes na resolução de situações problemas (SILVA, 2010).

No currículo, estão explícitos princípios que defendem o desenvolvimento de competências a partir do deslocamento do foco do ensino para a aprendizagem, "o aprender se sobrepõe ao ensinar", secundarizando o conhecimento e priorizando a criação de condições para que os alunos aprendam a se apropriar do conhecimento (CARVALHO; RUSSO, 2012).

Ao articular as competências para aprender como exigência da sociedade da informação, em que a escola não é mais a única detentora do conhecimento, essa concepção de educação difunde uma nova função para o professor: promover conhecimentos relevantes para a vida e que possam ser mobilizados em competências e habilidades.

No estado de São Paulo, desde meados dos anos de 1980, adotou-se como discurso oficial a concepção construtivista e, com o passar dos anos, sobretudo com a implementação do PSPFE, houve a intensificação do uso das "Pedagogias do Aprender a Aprender", ligadas ao universo ideológico do neoliberalismo (MARSIGLIA, 2012).

Entendia-se que o Caderno do Aluno, em suas situações de aprendizagem, apresentava as condições para que o foco fosse deslocado dos conteúdos para o desenvolvimento das competências e habilidades. Portanto não o utilizar nas aulas tirava a garantia de que o trabalho estivesse voltado para o desenvolvimento das competências e habilidades.

Já não se priorizavam mais os conteúdos, que até então eram o que norteava o trabalho dos professores. Naquele momento, eles tinham pela frente o desafio de tentar entender o que os idealizadores do material pensaram ao desenvolver cada atividade. Mediar o trabalho com aquelas situações de aprendizagem para que elas permitissem o desenvolvimento das habilidades propostas era uma tarefa que exigia tempo, estudo, orientação e contrariava a concepção de educação da maioria dos professores.

Depreende-se que a diferença de concepções de ensino, da reforma e dos professores é outro importante fator da rejeição que eles tiveram em relação ao material com viés construtivista.

Os professores não acreditam que o trabalho com o desenvolvimento das competências condiz com a realidade da sala de aula e têm convicção de que 
os resultados tão críticos da educação, marcados pela queda na qualidade das aprendizagens, vêm diretamente de anos relegando-se os conteúdos a um segundo plano. Previa-se ou intencionava-se a promoção de um aprendizado aberto, em que ao professor cabia ensinar "aprender a aprender". As falas dos sujeitos demonstram uma descrença em relação a isso e apontam para uma limitação no pleno desenvolvimento dos indivíduos (ARAÚJO, 2004).

Nossos alunos não estão sendo preparados para prestar o ENEM, eles não conseguem de jeito nenhum. E eu não diria que é só culpa do desinteresse deles. Eu acho que é todo o sistema educacional, inclusive o material didático nosso do estado de São Paulo, que eu acho que contribui para essa... esse resultado negativo para os nossos alunos. (Professor P5, 2018).

Os participantes da pesquisa demonstram que sabem, exatamente, o que devem ensinar e como o devem fazer, porém o material prescreve que seja realizado um trabalho que eles não acreditam ser o suficiente para a efetivação de uma aprendizagem significativa e para a formação integral do aluno.

Ele é muito confuso. Ele não tem uma sequência como devia ter. Tem poucas atividades. Então a gente tem que ficar complementando o tempo todo. Então eu acho uma perda de tempo isso daí, porque se eu tenho que ficar complementando eu uso a minha experiência e ensino do meu jeito. (Professor P1, 2018).

A divergência entre as concepções de ensino presentes no material e na formação dos professores foi reforçada quando eles apontaram, por exemplo, que o material pressupõe um aluno mais autônomo, que construa o conhecimento com a mediação do professor, e que o nível de dificuldade e a linguagem empregada no material estão muito aquém do que os alunos dominam.

Conclui-se que, ao mesmo tempo que o aluno não tem a autonomia necessária para o desenvolvimento das situações de aprendizagem presentes nos materiais do PSPFE, este tampouco dá espaço para a formação ou a atuação do professor enquanto mediador do processo de ensino-aprendizagem.

\subsection{Autonomia docente}

Buscou-se identificar a percepção dos professores em relação à sua autonomia diante do PSPFE e da proposta curricular. Partiu-se do pressuposto de que o PSPFE, formulado sem a participação docente e implementado sem considerar 
os contextos locais, poderia limitar a autonomia docente, reduzir a reflexão e a consciência do professor sobre o seu trabalho e capacidade de resistência docente, instituindo um profissional incerto, fruto de uma concepção de educação marcada pela racionalidade técnica.

Ao questionar os professores sobre sua percepção em relação à autonomia, notou-se que, entre os participantes da pesquisa, a cobrança realizada pela $D E$ e pelos gestores da escola quanto ao uso do material os faz avaliar que não há autonomia para tomar decisões em sala de aula. "Não, não tem. Nós estamos amarrados" (Professor P5, 2018).

Os professores sentem que a experiência que já tinham no período anterior ao currículo não foi respeitada e que o sentimento de desprofissionalização causou impactos no trabalho docente. Segundo Carvalho e Russo (2012), trata-se de consequências diretas do tipo de regulação que passou a vigorar com o PSPFE. "Eu acho que o professor tem que ter liberdade e não pode pegar uma experiência de 20 anos e jogar fora, né. Se eu sabia ensinar 20 anos atrás um determinado conteúdo, agora eu não sei mais?” [...] (Professor P1, 2018).

O PSPFE foi visto pelos professores como limitador de seu saber, sua prática, sua experiência acumulada em anos de docência e promoveu uma verdadeira cisão em alguns aspectos do trabalho docente (MACHADO, 2011). Tal cisão é fruto do crescimento de ideologias instrumentais defensoras da padronização de currículos para facilitar o controle e a administração do que acontece nas escolas. São verdadeiros "pacotes à prova de professor", que reduzem a autonomia docente e retiram do professor a possibilidade de realizar o planejamento curricular (GIROUX, 1997).

Sacristán (2000) ressalta que os guias curriculares, livros didáticos e avaliações externas vão influenciando os professores gradativamente e cumulativamente. Com o passar do tempo, as reações se apresentam na forma de adaptação, submissão, acomodação, resistência ou confronto.

Quando veio a implementação desse material foi muito conflito. O professor não queria trabalhar, o coordenador precisava pedir, né, e recebia cobranças dos seus superiores. Aícom o tempo colocou, depois coloca mais um pouquinho, aí o professor vai vendo que ninguém vai ceder ele vai ter que encarar. [...] Igual preso que entra na cadeia se bate, se bate se bate (risos) não tem como sair, ele tem que ficar, né (risos). (Professora P6, 2018). 
Constata-se, pelo depoimento exposto, que há entre o grupo professores que acreditam que o processo de resistência inicial foi seguido pela adaptação/ acomodação à reforma. Segundo Santos e Pierson (2015), conforme as atividades foram sendo realizadas nas aulas, os professores foram se adaptando, o que gerou uma modificação nos sentimentos e nas reações, conduzindo-os à aceitação.

Apesar dos riscos de acomodação, a realidade tem indicado uma situação muito adversa. É possível perceber que, mesmo que não tenham clareza a respeito disso, o processo de resistência mencionado por Sacristán (2000) se sobrepôs aos demais. "Agora tem coisas que eles fizeram que não dá para gente poder caminhar. Então me desculpa, eu pego e inverto, faço do jeito que eu acredito que os alunos entendam melhor" (Professor P7, 2018).

As colocações do professor P7 mostram as angústias vivenciadas por professores que estão há anos na rede de ensino e que lutam pela manutenção de sua autonomia. Esse professor não utiliza os materiais do PSPFE em suas aulas e adota uma metodologia de trabalho muito diferente da que é cobrada pelo programa.

Eu estou colocando cimento escondido, eu estou colocando o cimento que eu acho que tinha que ter porque senão essas paredes começam a trincar e você começa a perceber que os outros professores, por exemplo, as paredes estão trincando mas a minha não está. Então o que que eu faço, eu paro de colocar cimento também, né, se eu estou vendo que a do outro está trincando? Então, é nesse dilema que a gente vive. (Professor P7, 2018).

Comparando o ensino a uma construção, o professor alerta que, ao usar - Caderno do Aluno, é como se um pedreiro colocasse pouca massa nas paredes e estas começassem a trincar, podendo vir a cair, e afirma que, se fosse seguir o material, a aprendizagem não aconteceria, o ensino oferecido seria frágil e não atenderia às necessidades dos alunos.

Outros participantes da pesquisa relataram viver um dilema parecido: "Devo atender as reais necessidades dos alunos ou cumprir o material pelo qual serei cobrado?". A fala da professora de Língua Portuguesa (P6) expressa claramente esse dilema.

Então há um desencontro e eu preciso trabalhar aquilo. Então eu sinto que eu trabalhando aquilo eu sou honesta ao meu patrão, que seria, né, a parte pedagógica do Governo do Estado de São Paulo [...] mas com os alunos eu não sinto bem, porque eu gostaria de socorrer o aluno naquilo que ele está precisando. (Professora P6, 2018). 
Contreras (2002) faz importantes apontamentos nesse sentido.

A experiência concreta da educação excede a delimitação oficial de objetivos para que os docentes possam enfrentar os interesses e as necessidades daqueles com quem trabalham. E isso os situa inevitavelmente diante de conflitos e responsabilidades morais, diante da necessidade de encontrar uma resposta entre as exigências administrativas, os interesses da comunidade e as necessidades dos alunos. (CONTRERAS, 2002, p. 104).

Percebeu-se que os participantes da pesquisa vivenciam esse dilema e optam por adotar uma postura reflexiva diante da prática, constituindo um processo de reflexão na ação, o que transforma o professor em um pesquisador no contexto da prática. Os professores sabem muito bem o que fazer e como fazer, porém os materiais e os outros mecanismos adotados pela SEE tentam engessar sua prática. E, ao ignorarem as técnicas preestabelecidas, os professores não se sentem confortáveis, pois percebem que estão agindo contra o que já está determinado.

A gente se sente sozinho, a gente se sente nadando contra a correnteza e a gente se sente um pouco bandido, porque a gente se sente o tempo todo criticado por não estar fazendo o que o governo pediu para fazer [...] Isso deixa numa angústia muito grande. (Professor P7, 2018).

Lima (2001) define como infidelidade normativa esse processo de descumprimento de uma norma, de forma total ou parcial. A infidelidade normativa é fruto da fidelidade dos sujeitos aos seus interesses e propósitos, conforme constatou-se a partir da pesquisa empírica. Em uma rede de ensino extensa como a estadual, na qual as leis, decretos, resoluções e qualquer outro tipo de decisão são tomados/estabelecidos verticalmente, de fora para dentro da escola, com caráter normativo e impositivo, é comum encontrarmos a adoção de estratégias para burlá-los, conforme verificamos nas falas dos professores, já que "a administração central não é um corpo homogêneo e a legislação e outros normativos produzidos não constituem um bloco monolítico, coerente e articulado, tudo prevendo e regulamentando, de tal forma que nada nem ninguém Ihe poderá escapar" (LIMA, 2001, p. 59).

Destarte, as formas de resistência encontradas na realidade pesquisada mostra-nos que o trabalho docente não é apenas determinado normativamente e, muitas vezes, as tentativas de normatizar todo o processo de ensino-aprendizagem 
(o que ensinar, como ensinar, como avaliar) acaba conduzindo à insubordinação e ao descumprimento das regras (LIMA, 2001).

As formas de controle estabelecidas pela SEE esbarram nos objetivos e interesses dos professores e na experiência acumulada por eles ao longo de anos de trabalho pedagógico escolar. Os "saberes e fazeres de sua maestria" permanecem em sua prática cotidiana nas salas de aula, independentemente de qualquer política governamental que queira impor mudanças que para eles não são significativas (ARROYO, 2000, p. 17).

Como ressalta Arroyo, "o magistério incorpora perícia e saberes aprendidos pela espécie humana ao longo de sua formação" (ARROYO, 2000, p. 18), por isso os professores mantêm e reproduzem a herança de um saber específico, que os leva a travar embates e a resistir qualquer tentativa de mecanismos gerenciais usurparem o seu saber profissional. "Há uma resistente cultura docente" (ARROYO, 2000, p. 19).

Por mais que as políticas educacionais tratem os professores como cata-ventos, obrigados a girar conforme as demandas políticas e tecnológicas, estes têm resistido a partir da reafirmação da especialidade de sua ação, do seu saber-fazer, planejar e intervir (ARROYO, 2000).

Nota-se um abismo entre o que foi idealizado pela SEE e a apropriação dos materiais do PSPFE pelos professores, pois, no uso cotidiano, eles os recriam. Então, por mais que o professor já não consiga determinar todas as ações, ele ocupa um saber estratégico que lhe permite criar novas possibilidades diante da política. Por mais que os materiais do PSPFE tenham trazido transformações ao cotidiano escolar e ao trabalho docente, o saber dos professores ainda se sobrepõe a tudo o que lhes é imposto. Os professores não deixam de usar os materiais, porém lhes dão novos significados, já que dominam as múltiplas formas de conhecimento (CANTAZARO, 2012).

\section{CONSIDERAÇÕES FINAIS}

Para atender às novas demandas resultantes da reestruturação do capitalismo, adotou-se uma nova perspectiva pedagógica, a "Pedagogia das Competências", vista como responsável pela formação de sujeitos capazes de mobilizar conhecimentos e saberes na resolução de situações-problema (SILVA, 2010). 
Essa perspectiva defende o deslocamento do foco do ensino da transmissão de conteúdos para a construção de competências, pois acredita-se que a consolidação do processo ensino-aprendizagem ocorra a partir da interação do sujeito com o meio, restando ao professor o papel de facilitador/mediador desse processo (RAMOS, 2002).

No estado de São Paulo, a política educacional foi sendo desenhada nesses moldes, sobretudo a partir de 1995, quando uma série de reformas foram implementadas na rede de ensino paulista. Formas empresariais de gestão foram incorporadas na educação e o processo decisório concentrou-se ainda mais nas altas hierarquias da SEE, sem uma participação efetiva de outros sujeitos (RAMOS, 2013).

Usando como argumentos os baixos índices de desempenho dos alunos das escolas públicas estaduais paulistas e a falta de uma base curricular comum, o PSPFE e uma nova proposta curricular foram implementados em toda a rede, desconsiderando as particularidades locais.

Com esta pesquisa, pode-se constatar que a verticalidade na tomada de decisão e o silenciamento imposto aos principais atores da ação educativa apresentaram-se entre os fatores de repulsão a essa política. Os reformistas desconsideraram que é o professor quem conhece o aluno e a realidade que o cerca e que, portanto, cabe a ele a construção de um currículo contextualizado.

Constata-se ainda que, por mais que a SEE se valera de uma série de mecanismos para garantir a implementação/consolidação da reforma, os instrumentos não foram eficazes na realidade pesquisada, já que os participantes da pesquisa não os associaram à política em questão.

No entanto esses materiais trouxeram muitas transformações à prática docente. O caráter prescritivo dos materiais fez com que os professores se sentissem obrigados a trabalhar com uma concepção de ensino que negava seus preceitos e ignorava seu saber-fazer.

Conclui-se que, apesar da força inegável dessa política, os participantes da pesquisa não são meros reprodutores da proposta curricular prescrita pela SEE. Pelo contrário, deram novos significados aos materiais do SPFE, adequando-os a seu favor na ação educativa.

Apesar de algumas características dos materiais os isolarem, dificultarem a interdisciplinaridade e a construção do trabalho coletivo, os professores criaram 
estratégias de resistência e construíram um trabalho criativo, fugindo das amarras da racionalidade técnica imposta pelos materiais.

Enquanto as políticas educacionais forem assunto de gabinete, pensadas e planejadas por experts que nunca entraram em uma sala de aula, elas não se consolidarão no cotidiano escolar. É preciso olhar de perto esse cotidiano repleto de angústias, de cobranças, de demandas que não vêm sendo consideradas. Os professores recebem as reformas pensadas distantes da escola com estranheza e desprovidas de sentido.

Espera-se que este trabalho contribua para reflexões acerca das políticas educacionais e seus impactos no chão da escola. A escola é viva, dinâmica, nela vemos o reflexo da sociedade com todas as suas contradições e conflitos. Os professores são sujeitos históricos que constroem e reconstroem a todo tempo essa historicidade, são detentores de saberes e reafirmam a todo tempo a especialidade de sua ação, a ação educativa. Qualquer política voltada à educação precisa considerar essas especificidades.

\section{REFERÊNCIAS}

ARAÚJO, Ronaldo M. As referências da Pedagogia das Competências. Perspectiva, Florianópolis, v. 22, n. 2, p. 497-524, jul./dez. 2004

ARROYO, Miguel. Ofício de mestre. Petrópolis: Vozes, 2000.

CANTAZARO, Fabiana O. O Programa São Paulo Faz Escola e suas apropriações no cotidiano de uma escola do Ensino Médio. 2012. 126 f. Dissertação (Mestrado em Educação ) Universidade de São Paulo, São Paulo, 2012.

CAPALBO, Roberta B. Política Pública de Educação e Proposta Curricular do Estado de São Paulo: Percepções sobre a eficácia. 2010. 136 f. Dissertação (Mestrado em Educação) Pontifícia Universidade Católica de São Paulo, São Paulo, 2010.

CARVALHO, Celso do Prado Ferraz; RUSSO, Miguel Henrique. Educação, regulação e políticas educacionais: o contexto paulista. Eccos Revista Científica, São Paulo, n. 29, p. 135-50, set./dez. 2012.

CASTRO, Maria Helena Guimarães. Nova agenda da educação de São Paulo. Folha de São Paulo, São Paulo, 2007. Disponível em: https://www.saopaulo.sp.gov.br/spnoticias/ na-imprensa/artigo-nova-agenda-da-educacao-de-sao-paulo-por-maria-helena. Acesso em: 10 jan. 2020. 
CONTRERAS, José. A autonomia de professores. São Paulo: Cortez, 2002.

DI GIORGI, Cristiano Amaral Garboggini; MILITÃO, Silvio Cesar Nunes; MILITÃO, Andréia Nunes; PERBONI, Fabio; RAMOS, Regina Célia; LIMA, Vanda Moreira Machado; LEITE, Yoshie Ussami Ferrari. Uma proposta de aperfeiçoamento do PNLD como política pública: o livro didático como capital cultural do aluno/família. Ensaio: Avaliação e Políticas Públicas em Educação, Rio de Janeiro, v. 22, n. 85, p. 1027-56, 2014.

GENTILI, Pablo. A falsificação do consenso: simulacro e imposição na reforma educacional do neoliberalismo. 3. ed. Petrópolis: Vozes, 1998.

GIROUX, Henry. Os professores como intelectuais transformadores: rumo a uma pedagogia crítica da aprendizagem. Porto Alegre: Artes Médicas, 1997.

LIMA, Licínio C. A escola como organização educativa: uma abordagem sociológica. São Paulo: Cortez, 2001.

MACHADO, Janete da Costa. Trabalho e currículo oficial: contradições e tensões no modo de ser professor contemporâneo. Reflexões sobre os livros-textos. 2011. 248 f. Dissertação (Mestrado em Educação) - Pontifícia Universidade Católica de São Paulo, São Paulo, 2011.

MALDONADO, Luís R. S. Reformas educacionais na perspectiva de docentes: o Programa São Paulo Faz Escola. 2013. 121 f. Dissertação (Mestrado em Educação) - Universidade de São Paulo, São Paulo, 2013.

MARSIGLIA, Ana Carolina. G. O construtivismo como discurso pedagógico oficial na rede de ensino paulista a partir da década de 1980. Revista HISTDEBR, v. 12, n. 45, p. 241-62, 2012.

MUNAKATA, Kazumi. O livro didático e o professor: entre a ortodoxia e a apropriação. In: MONTEIRO, Ana Maria; GASPARELLO, Arlete M., MAGALHÃES, Marcelo de Souza. (Org.). Ensino de História: sujeitos, saberes e práticas. Rio de Janeiro: FAPERI/Manad, 2007.

RAMOS, Géssica P. A política educacional paulista (1995-2010) e seus impactos na identidade da escola e do professor. Revista Brasileira de Política e Administração da Educação, v. 29, n. 3, p. 537-56, set./dez. 2013.

RAMOS, Marise N. A pedagogia das competências: autonomia ou adaptação. 2. ed. São Paulo: Cortez, 2002.

RUA, Maria das Graças. Para aprender políticas públicas. 3. ed. Brasília: IGEPP, 2013. 
SACRISTÁN, José G. O currículo: uma reflexão sobre a prática. Porto Alegre: ARTMED, 2000.

SANTOS, Rita C; PIERSON, Alice H. C. As reações dos professores de ciências diante da implantação de novo currículo na rede estadual paulista. Ensaio: Pesquisa em Educação em Ciências, Belo Horizonte, v. 17, n. 03, p. 585-605, 2015.

SILVA, Marco A. A fetichização do livro didático no Brasil. Educação e Realidade, Porto Alegre, v. 37, n. 3, p. 803-21, set./dez. 2012.

SILVA, Paulo Aparecido Dias. Pedagogia das competências e construtivismo: aproximações no contexto da reestruturação produtiva. In: ENCONTRO DE PÓS-GRADUAÇÃO EM EDUCAÇÃO, 1., 23-26 nov., 2010, Porto Velho. Anais [...]. Porto Velho: Editora da Universidade Federal de Rondônia, 2010. p. 01-12.

TORRES, Rosa M. Política educacional. Rio de Janeiro: De Paulo Editora, 2000.

TRIVIÑOS, Augusto. Introdução à pesquisa em ciências sociais: a pesquisa qualitativa em educação. São Paulo: Atlas, 2011.

\section{Sobre os autores:}

Daiani Vieira Ortega: Mestra em Educação pelo Programa de Pós-Graduação em Educação da Universidade Estadual Paulista Júlio de Mesquita Filho (UNESP) Campus de Presidente Prudente, na linha de pesquisa Formação dos Profissionais da Educação, Políticas Educativas e Escola Pública. Bacharel e licenciada em Geografia pela UNESP-FCT - Campus de Presidente Prudente. Professora efetiva da rede estadual de ensino. Atualmente, é professora coordenadora na Escola Estadual Prof. Durvalino Grion, em Adamantina. Membro do Grupo de Estudos e Pesquisas em Políticas Educacionais e Práticas Educativas (GEPPOPE). Área de interesse: Educação, Formação de Professores e Políticas Educacionais. E-mail: daivgeografa@gmail.com, Orcid: https://orcid.org/0000-0003-0949-4644.

Silvio Cesar Nunes Militão: Doutor e mestre em Educação pela Universidade Estadual Paulista Júlio de Mesquita Filho (UNESP). Graduação em Ciências Sociais - Licenciatura Plena pela UNESP e em Pedagogia pela Universidade Nove de Julho (UNINOVE). Atualmente, é professor assistente doutor do Departamento de Didática da UNESP (FFC - Campus de Marília) e docente do Programa de Pós-Graduação em Educação da UNESP (FCT - Campus de Presidente Prudente). É líder do Grupo de Estudos e Pesquisas em Políticas Educacionais e Práticas Educativas (GEPPOPE). Tem experiência na área de Educação, com ênfase em 
Política Educacional, atuando principalmente nos seguintes temas: neoliberalismo, organismos internacionais, descentralização, municipalização do ensino, financiamento da educação (FUNDEF/FUNDEB), educação municipal, adoção de sistemas apostilados de ensino e educação de tempo integral.E-mail: scmilitao@gmail.com, Orcid: https://orcid.org/0000-0003-2094-1193.

\section{Recebido em: 10/03/2020}

Aprovado em: 31/01/2021 
